\title{
Design and Implementation of a SMART Learning Environment for the Upskilling of ICT professionals in Mauritius
}

\author{
Roopesh Kevin Sungkur ${ }^{1}$ and Manoj Maharaj ${ }^{2}$ \\ ${ }^{1}$ Univ Mauritius \\ ${ }^{2}$ University of KwaZulu-Natal
}

November 1, 2020

\begin{abstract}
Teaching and Learning confined to within the four walls of a classroom or even online Learning through Massive Online Courses (MOOCs) and other Learning Content Management Systems (LCMS) are no longer seen as the optimal approach for competency and skills development, especially for working professionals. Each of these busy learners have their own training needs and prior knowledge. Adopting the one-size-fits-all teaching approach is definitely not effective, motivating and encouraging. For some learners, the content might be too easy and for others, it might be too difficult. This is why this research presents the use of SMART Learning Environment that makes use of Intelligent Techniques to personalise the learning materials for each learner. It has been observed that on one hand the country is not able to provide the required number of IT professionals with the desired skills and on the other hand, the number of unemployed graduates in areas other than IT is increasing. This mismatch in skills is becoming a pressing issue and is having a direct impact on the ICT Sector, which is one of the pillars of the Mauritian Economy. This research, therefore, besides proposing a novel approach to learning, also attempts to address an issue of national importance. The major findings of this research were that personalisation of learning materials through the use of a SMART Learning Environment can be used to address the training needs of Cybersecurity professionals in Mauritius, by offering a more effective, engaging and motivating learning experience.
\end{abstract}

\section{Hosted file}

SLE180920_noauthors.pdf available at https://authorea.com/users/372040/articles/490190design-and-implementation-of-a-smart-learning-environment-for-the-upskilling-of-ictprofessionals-in-mauritius 